\title{
REAL-TIME STRUCTURAL MONITORING OF BIBI-KHANUM IN SAMARKAND (UZBEKISTAN) COMBINED WITH SUBSEQUENT LASER SCANS
}

\author{
SHAKHZOD M. TAKHIROV ${ }^{1 *}$, ILYAS ARIPOV ${ }^{2}$ AND DAVRON MATRASULOV ${ }^{2}$ \\ ${ }^{1}$ Structures Laboratory, Civil and Environmental Engineering Department, University of California, \\ Berkeley; 337 Davis Hall, Berkeley, CA 94720; email: takhirov@berkeley.edu; \\ https://ce.berkeley.edu (*corresponding author) \\ ${ }^{2}$ Turin Polytechnic University in Tashkent, 100095, Tashkent, Uzbekistan email: iljasar@mail.ru, \\ dmatrasulov@gmail.com; https://polito.uz/en/
}

Keywords: Structural Health Monitoring, Seismic Assessment, Laser Scanning, Seismometers, Real-time monitoring, Bibi-Khanum, Samarkand, Great Silk Road.

\begin{abstract}
The Bibi-Khanum Mosque was originally built in 1399-1405 and was one of the largest and most magnificent mosques in the Islamic world during the $15^{\text {th }}$ century. In recent years, the monument underwent several complex reconstructions. Among many other major restoration activities, the inner arch of the portal that collapsed in the 1897 earthquake was restored. The monument has been restored to be one of the best shapes in its history, thus it has become essential to conduct continuous structural health monitoring (SHM) of it to ensure its preservation for humanity. The SHM became the main objective of an ongoing extensive project, some results of which are presented herein. The structural health monitoring consisted of three major phases. The first phase includes a real-time monitoring of the monument by seismometers, which are permanently installed throughout the monument. They are used to monitor the effects of large and small earthquakes and ambient vibrations on the resonant frequencies of all major structures of the monument. By utilizing a system identification approach, the possibility of a structural anomaly development can be detected from the change in its resonance frequency. The second phase consists of subsequent laser scanning that is deployed to monitor anomalies of the monument's geometry in 3D. The monument's geometry is captured as a collection of points, which is called a "point cloud". Laser scanning is planned to be conducted several times a year to capture global movements of the monument due to changes in the elevation of the underground water table in rainy and dry seasons. The third phase focuses on a development of a finite-element (FE) model based on the as-found geometry of the point clouds. It is calibrated based on the collected data to ensure acceptable correlations with the results of the measurements. The FE model is generated for use in future restoration efforts to evaluate the performance and efficiency (if any) of the proposed restoration measures. Based on the results of numerical simulations and structural health monitoring, preventive measures will be developed. In addition, recommendations for further preservation of the historic monument will be developed. This paper describes the preliminary results of the first phase and current results of the second phase of this multiphase project.
\end{abstract}




\section{INTRODUCTION}

The Bibi-Khanum Mosque was originally built in 1399-1405 and was one of the largest and most magnificent mosques in the Islamic world during the $15^{\text {th }}$ century. The heritage structure was studied by Ratiia in the 1940s. Based on these studies, Rattia developed the first restoration plan drawings in his book published in 1950 [1]. One of these drawings is reproduced in Figure 1. As shown in the plan drawing, the Bibi-Khanum Mosque was built as a courtyard ensemble with three domed masonry structures (mosques) along the walls. The main mosque is located on the west side, and two smaller mosques are located along the north and the south walls. The Bibi-Khanum Mosque was also studied in [2].
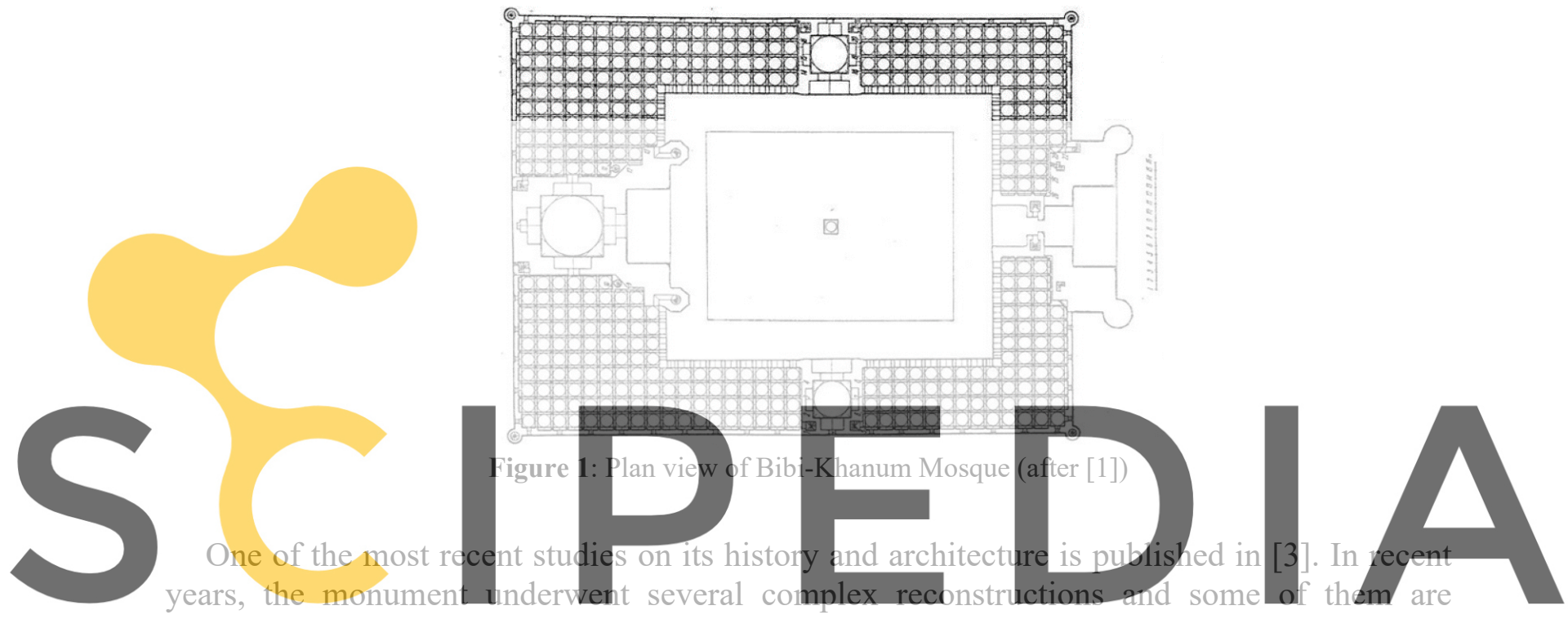

mentioned in [4]. Among many other major restoration activities, the inner arch of the portal

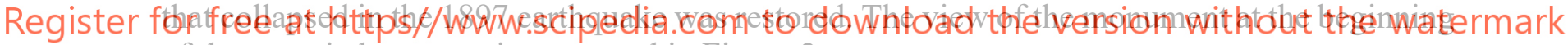
of the twentieth century is presented in Figure $2 \mathrm{a}$.

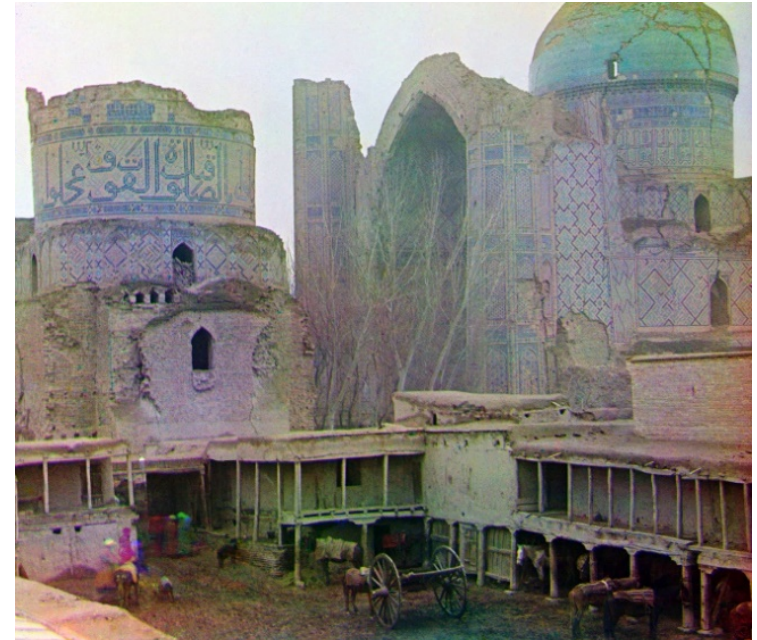

a) Photo dated by $1905-1915$

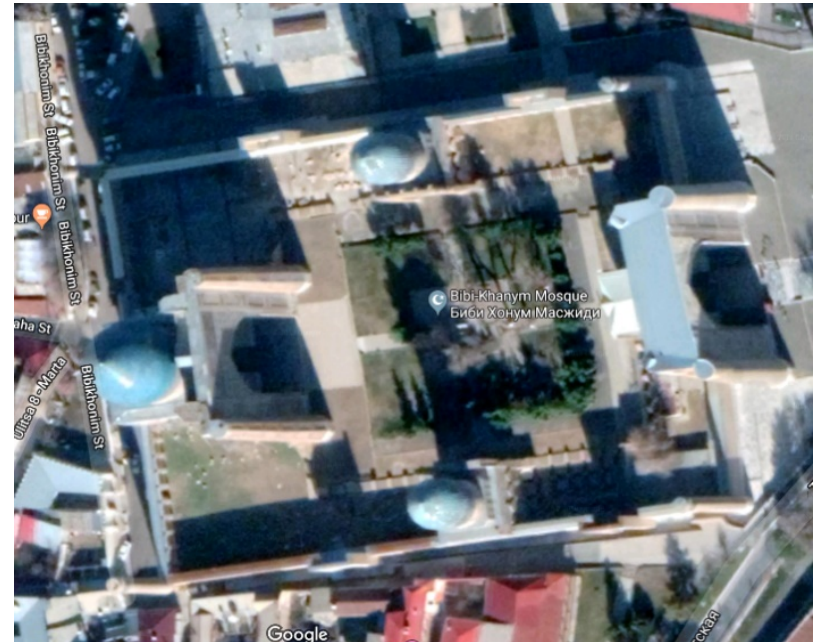

b) Aerial view (Google maps)

Figure 2: The Bibi-Khanum Mosque 
The photograph presented in Figure 2a was taken between 1905 and 1915 by color photography pioneer Sergei Mikhailovich Prokudin-Gorskii. It shows the mosque's appearance after its collapse in the 1897 earthquake. Figure $2 \mathrm{~b}$ shows its aerial view taken from Google maps.

\section{LASER SCANNING}

The Bibi-Khanum Mosque was scanned in July 2019. Observations indicated that the mosque had undergone a recent reinforcement and some of the work was ongoing. To capture the current geometry of the monument, a terrestrial scanner was deployed. A laser scanner from Leica Geosystems, Scan Station C10 [5], was utilized for the project.

The scanning was conducted from seven stations to capture the exterior and interior walls of the monument. No reference targets were used in the laser scanning process. To stitch the point clouds collected from each station, a point cloud to point cloud matching was utilized. A complete registration of the point clouds collected from these seven stations is presented in Figure $3 \mathrm{a}$ and the registration was conducted in Cyclone [6]. Figure 3a also shows the locations of the stations (yellow triangular icons) on the fully registered point cloud of the monument. The point cloud was colored based on the photos obtained from the scanner's built-in camera. Figure $3 \mathrm{~b}$ shows a typical point cloud of the mosque with its natural colors. A view from the ground level is shown here.
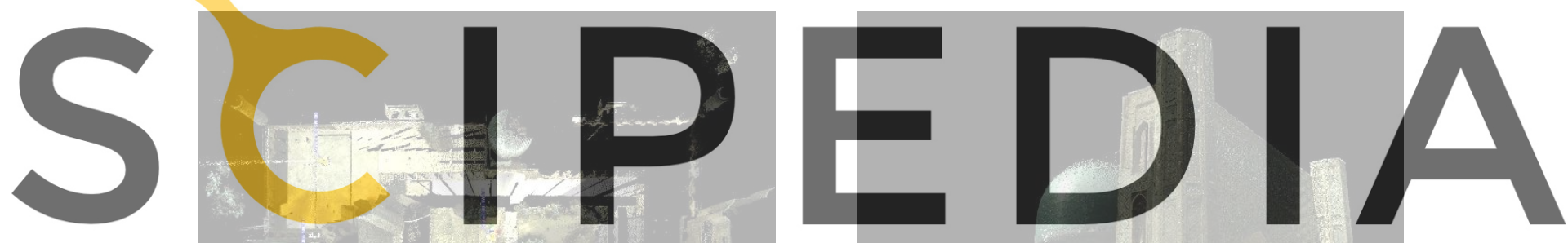

Register for free at https//www.scipedia.com to
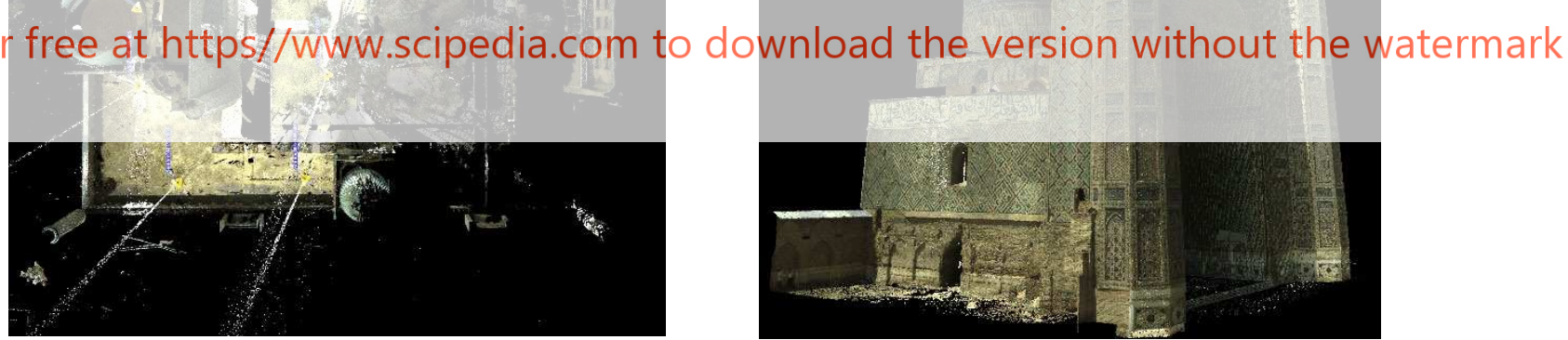

a) TruView with stations

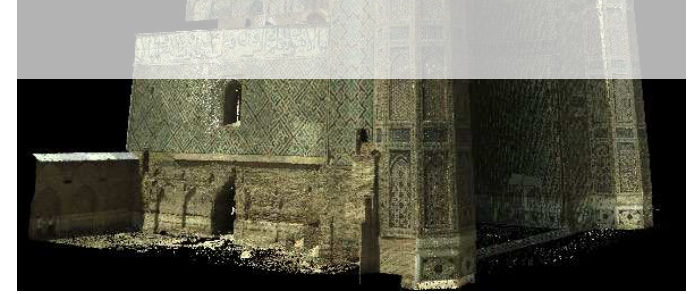

b) Ground view of point cloud: main mosque

Figure 3: Fully registered point cloud combining seven stations

The remaining analysis of the point cloud was conducted in a Matlab environment [7]. For the convenience of presentation and clarity of discussion, several local coordinate systems were introduced. It is worth noting that all these coordinate systems can be correlated to a single global coordinate system (GCS). The latter GCS can be geo-referenced if needed.

\subsection{Analysis of main mosque's entrance (portal)}

The portal of the main mosque is presented in Figure 4. A new coordinate system with the 
origin at ground level and coinciding with the middle of the portal's arch was introduced.

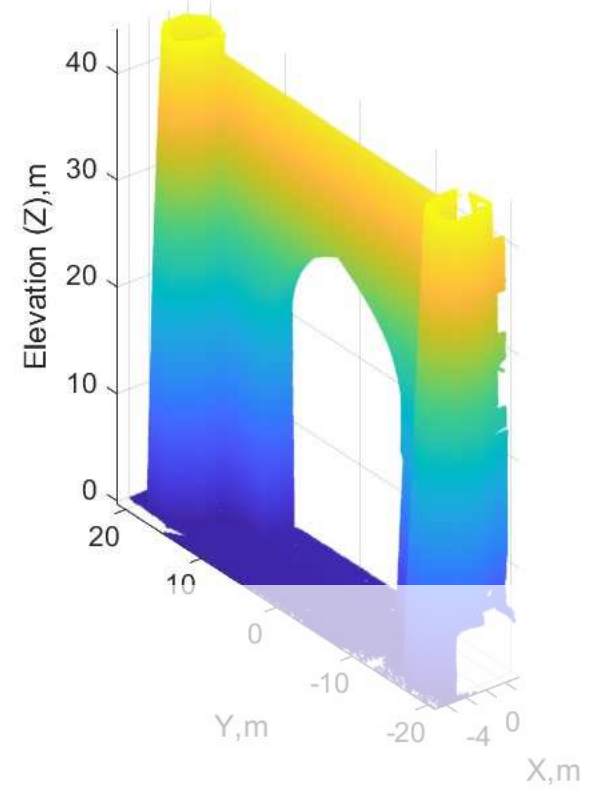

Figure 4: Main mosque's portal

Figure 5a shows

inclination of the surface th

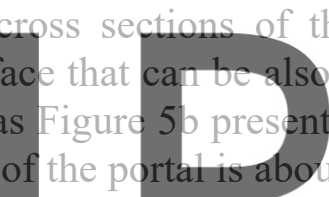

related to the wall

wall's cross sections, whereas Figure $5 \mathrm{~b}$ presents horizontal cross section

inclination on the top of the portal is about $0.25 \mathrm{~m}$ between the
$\mathrm{m}$. Most likely this difference in inclination is related to the ag

represent any structural concern as it did in the case of

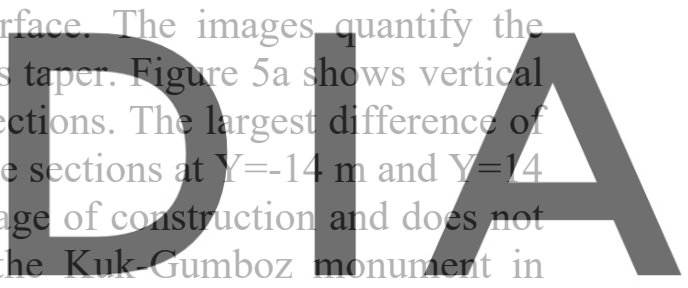

Shakhrisyabz (Uzbekistan) [8]. Nevertheless, subsequent laser scanning expeditions are

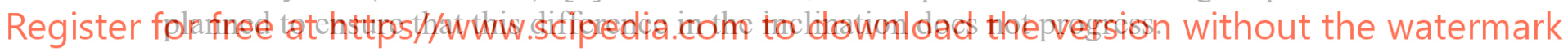

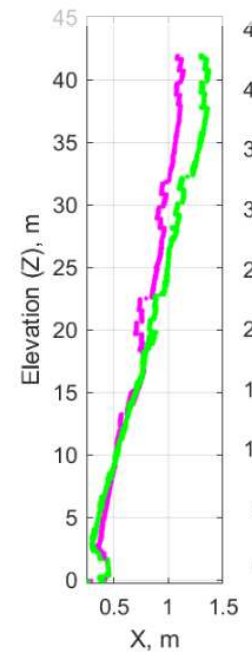

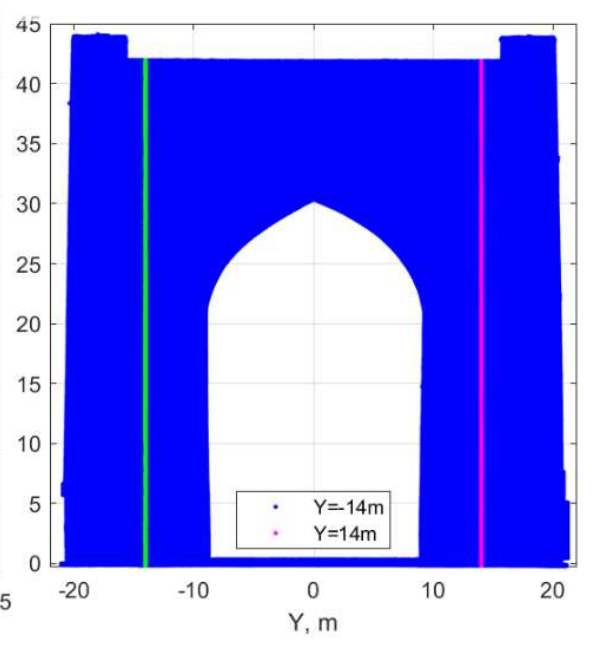

a) Vertical
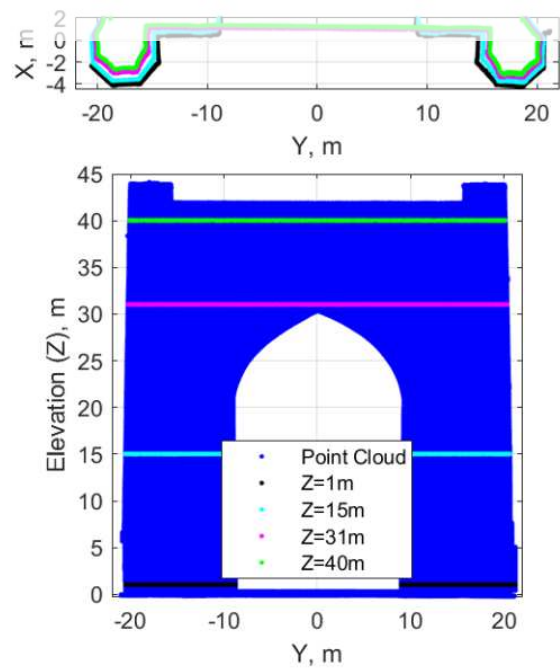

b) Horizontal

Figure 5: Cross sections of the frontal surface of the portal 
Figure 6 shows a contour map of the inclinations of the portal. The points are colored based on the distance from the vertical plane. This color map clearly shows the difference in the inclinations on the left and right sides of the portal as was mentioned earlier in the example of the two vertical sections. As shown in the image, the inclination of the portal is gradually increasing towards the top left side. Since the region of interest is relatively narrow, the minarets on both sides of the portal are not presented in Figure 6.

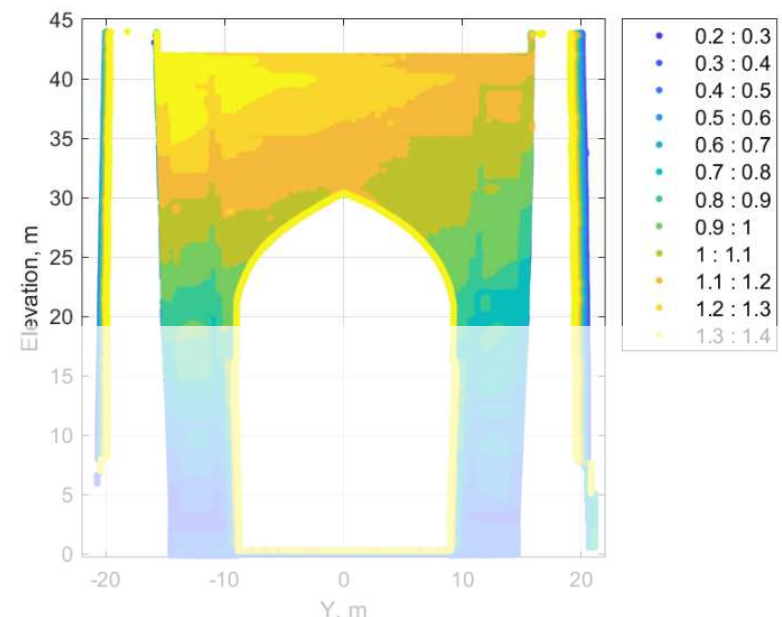

Figure 6: Color map of portal's inclinations (legend's units are meters)
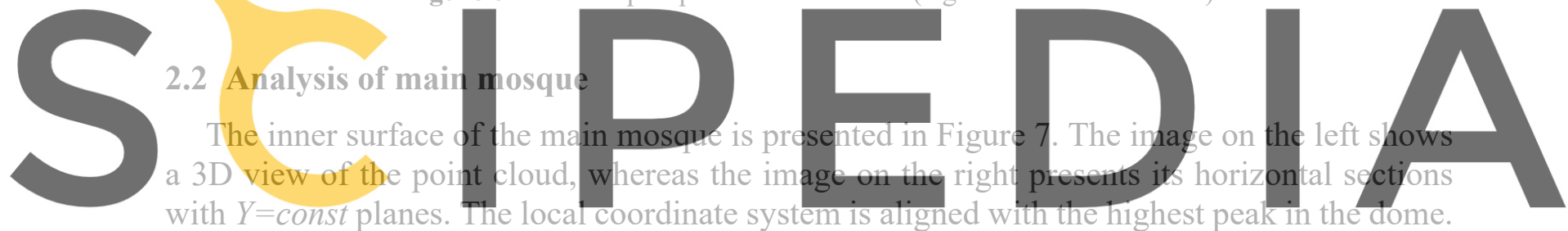

with $Y=$ const planes. The local coordinate system is aligned with the highest peak in the ciome.

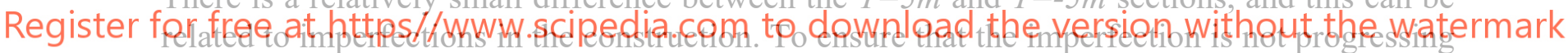
or creating structural deficiencies, a follow-up laser scan is planned in several months.

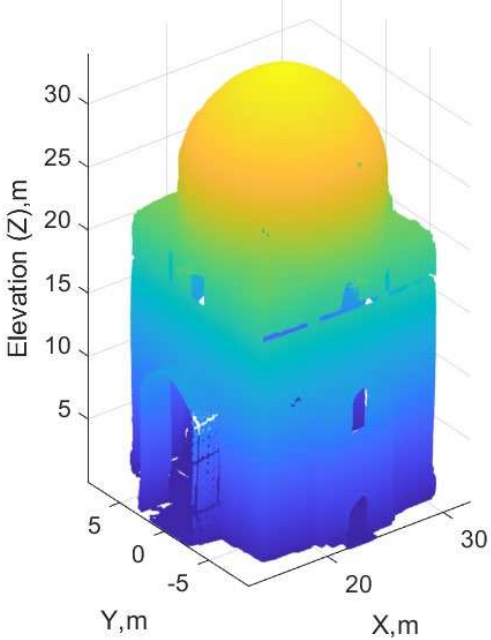

a) $3 \mathrm{D}$ view
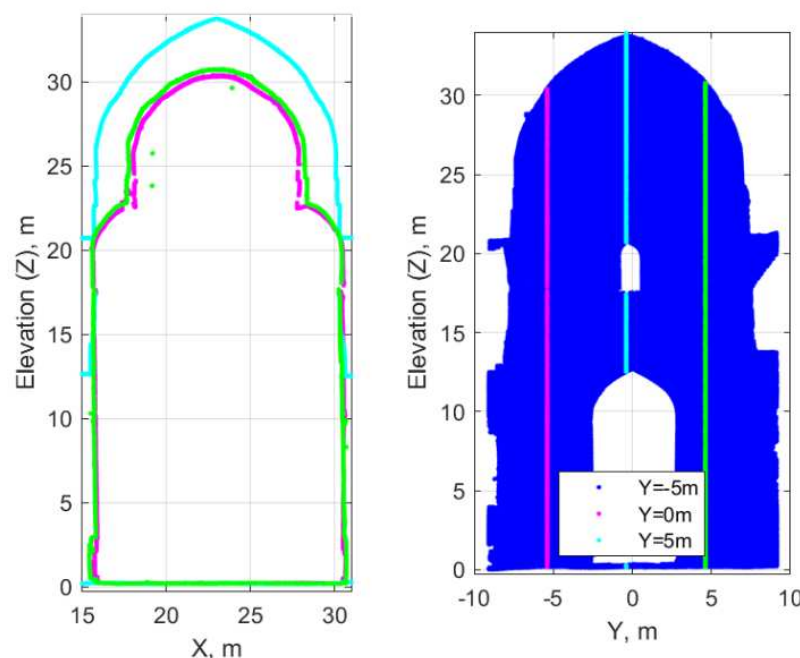

b) Cross sections with vertical plane $Y=$ const.

Figure 7: Inner surface of main mosque 


\subsection{Analysis of main mosque's walls}

Analysis of the walls' point cloud is discussed herein. Due to the size limitations of this paper, only two walls of the main mosque are discussed below. The inner surface of the east wall is presented in Figure 8a. It shows a sagging in its top middle portion right under the dome. Several cracks serve as evidence that the structural integrity of this wall needs to be investigated and addressed. In the case of the south wall shown in Figure 8b, there is no sagging, this most likely relates to a concrete retrofit that is incorporated into the wall.

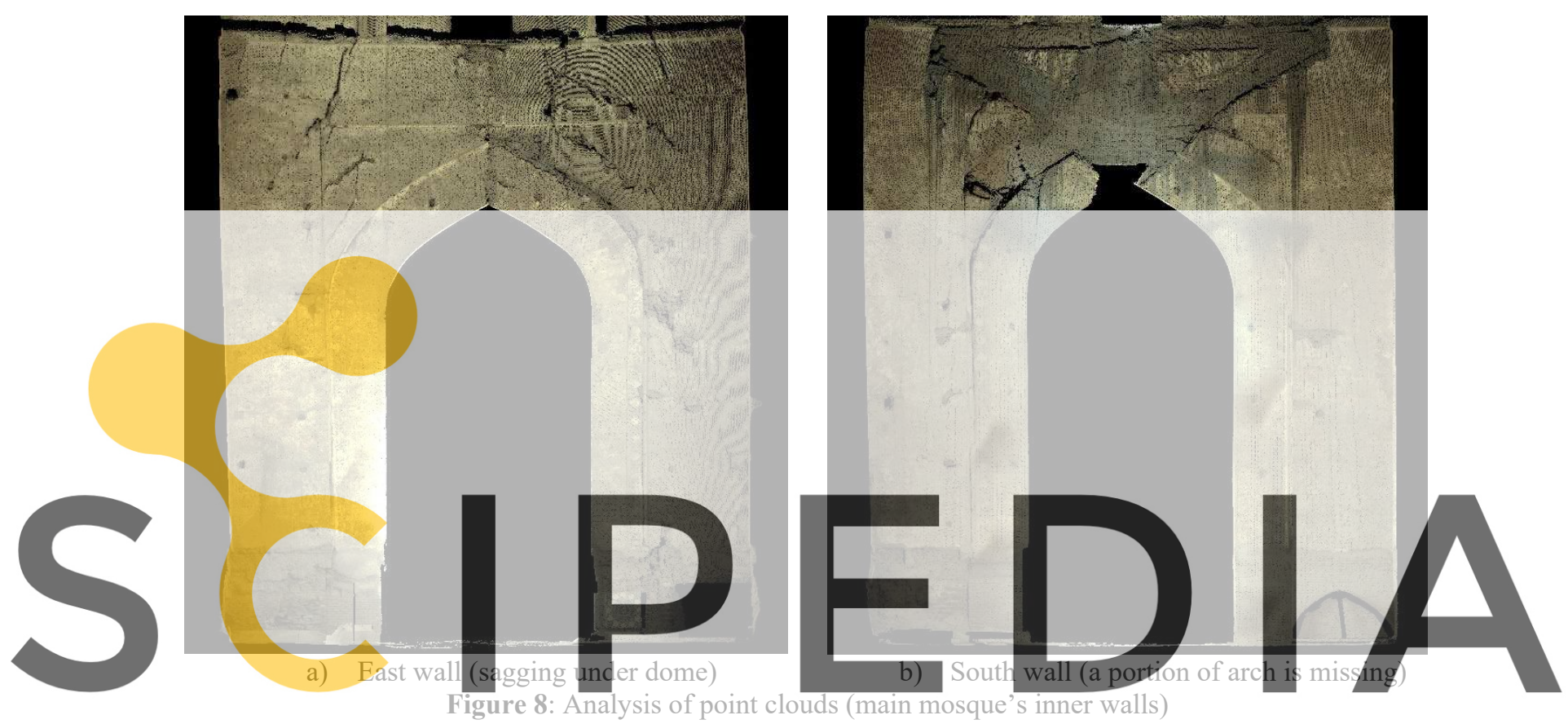

Register for free at https//www.scipedia.com to download the version without the watermark As can be seen from the right image, a large volume of reinforced concrete was introduced above the arch. The arch is missing a piece at its tip. The reinforced concrete is most likely very beneficial for holding together the failing parts of the wall; however, it may result in an introduction of a large weight at higher elevation of the building due to the large difference in density of concrete and masonry. The latter can result in significant changes in the dynamics of the whole structure. In the earlier studies $[9,10]$ an experimental investigation of a typical brick material was conducted. The test results show that the density of the bricks is about $1,600 \mathrm{~kg} / \mathrm{m}^{3}$. The latter test results are consistent with the results obtained for the bricks recovered from heritage buildings in Europe [11]. Hence, the bricks are about 1.5 lighter than the reinforced concrete, the density of the latter is typically assumed as $2,400 \mathrm{~kg} / \mathrm{m}^{3}$.

The following conclusions can be drawn from the analysis of the walls' point clouds. There is a large difference between the east and south walls that will result in a difference in their structural performance under static loads. In addition, a large mass of reinforcement in the south wall can result in large differences in structural performance during seismic events.

To assess the performance of the building with such large irregularities, extensive monitoring is required. The latter is addressed by utilizing seismometers at critical locations throughout the monument. 
The out-of-plane inclinations of the east wall is presented in Figure 9a. An estimate of the sagging at the lowest point of the east wall in respect to its highest point (green line) is presented in Figure 9b. The sagging can be closely approximated by a parabolic line as indicated by a red dashed line in the top image of Figure $8 \mathrm{~b}$. Based on the availability of future funding, the east wall will be instrumented by position sensors to monitor sagging and crack development.
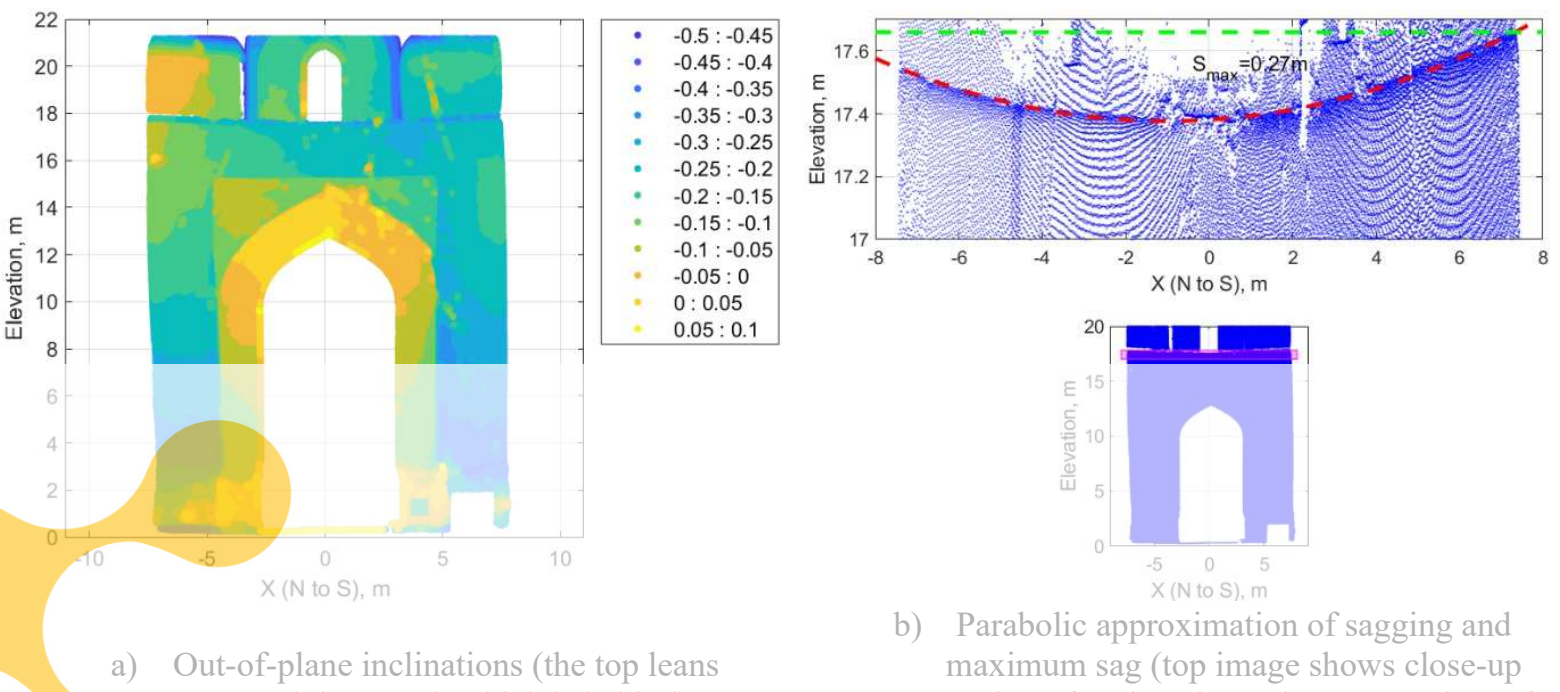

b) Parabolic approximation of sagging and maximum sag (top image shows close-up
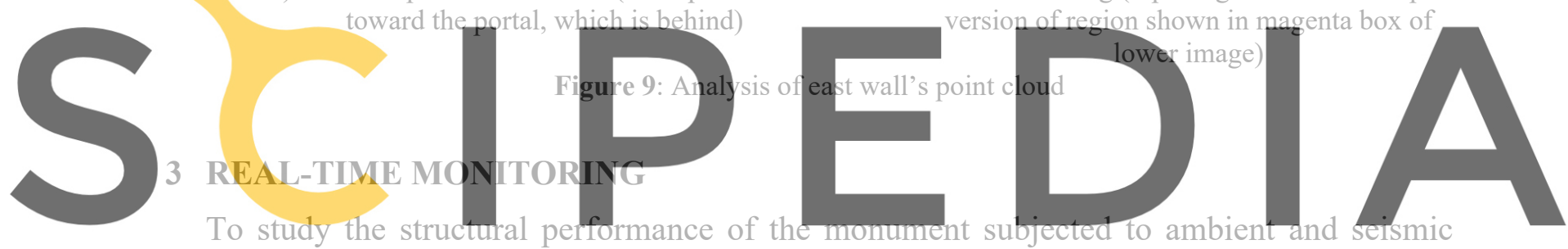

excitations, an array of tri-axial seismometers is installed. The seismometers are used to

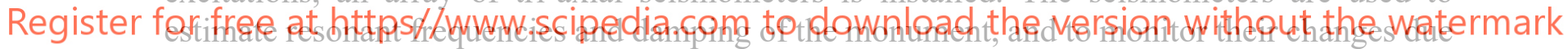

to structural anomalies, if any. The process of installing seismometers is completed. In addition,

a power supply and reliable internet connections are established.

The seismometer based SHM will register not only ambient vibrations, but also the frequent local earthquakes in Uzbekistan and Tajikistan. Monitoring the modal parameters (resonant frequencies and critical damping values) of the monument in real-time is the main objective of SHM and will also serve for rapid-response actions in case of significant changes of modal parameters.

\subsection{Preliminary instrumentation layout}

A layout of the instrumentation is presented in Figure 10. As seen in the image, fifteen triaxial seismometers are installed at strategic locations throughout the monument. The main entrance portal to the whole ensemble is instrumented by four seismometers. Smaller structures on the north and south sides of the ensemble are instrumented by three seismometers. The mosque is instrumented by eight seismometers, from which four seismometers monitor the vibrations of the mosque's portal and the other four seismometers are installed on the main structure of the mosque. The latter set includes one seismometer to monitor the dome's 
vibrations. A summary of the accelerations' locations is presented in Table 1.

It is worth noting that the outer surface of the monument is protected by decorative tiles and as such, the deformations measured on the outer surface may not reflect inner deformations. In this case, other measuring techniques need to be implemented. For example, a penetrating georadar can be utilized.

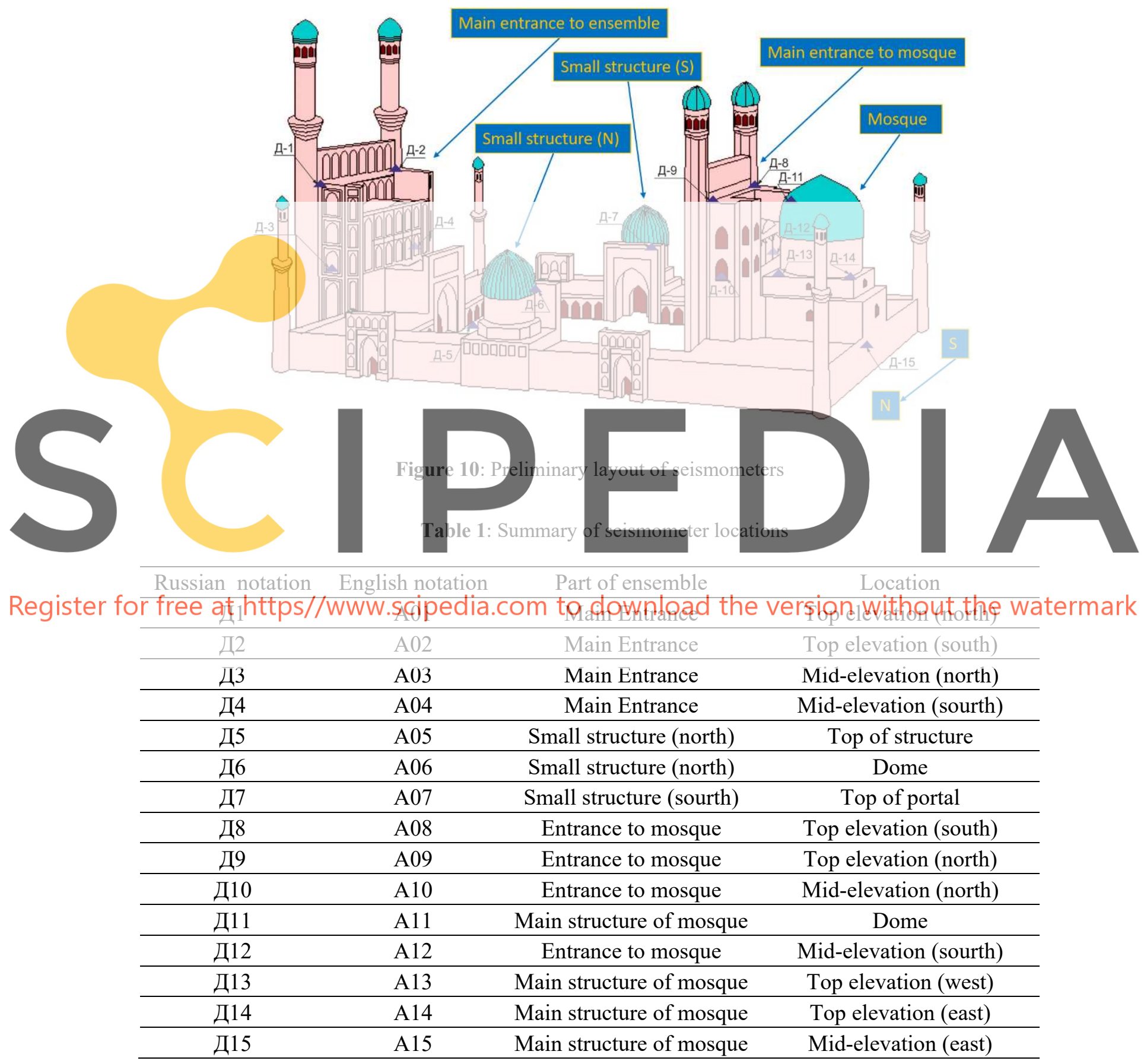




\subsection{Finite element modeling and optimization of seismometer layout}

The instrumentation layout shown in Figure 10 was considered to be the first step in determining of the best possible location for the seismometers. In the next step of the study, a finite element model of the monument will be developed which will reflect all anomalies captured by the laser scanner. The finite element model will be calibrated by utilizing the ambient test data collected from the instruments at the locations presented in Figure 10. As a result, a finite element model closely replicating the actual monument will be developed. The model will be used in the optimization process to identify the best locations for the seismometers. Depending on the results of this optimization study, the seismometers will be rearranged at the newly identified locations. Based on the results of ambient vibration tests from the new locations, the finite element model will be updated. This part of the project is ongoing.

\section{CONCLUSIONS}

The Bibi-Khanum monument is a historic monument, which was repaired and/or reinforced several times throughout its long history. The materials and methods used in these efforts vary widely. As a result, the monument represents a building, of which its structural performance is difficult to assess by conventional means. To address the issue, this paper highlights the usage of modern technologies to monitor the monument and predict its structural performance.

The results of this study show that the current anomalies of the monument can be

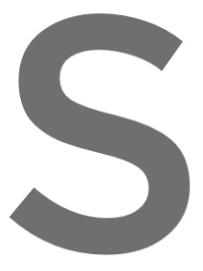
captured with structural and any. Future subsequential The next steps
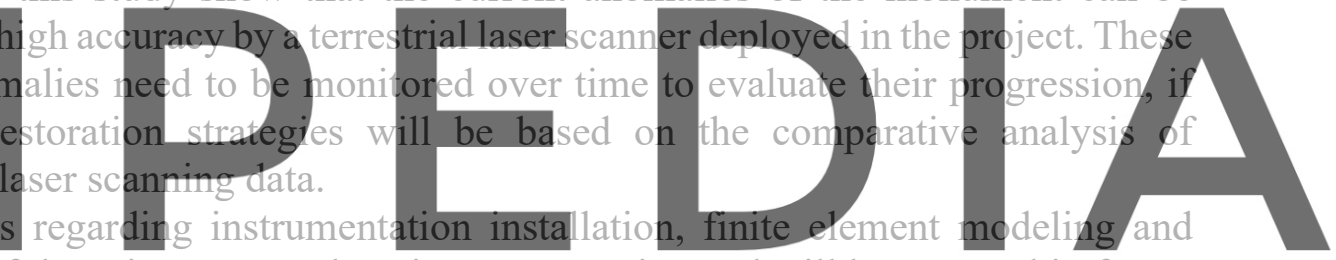

optimization of the seismometers locations are ongoing and will be reported in future

Register for free Bublifetjopswwww.scipedia.com to download the version without the watermark

\section{ACKNOWLEDGEMENTS}

A photograph presented in Figure 2a was taken between 1905 and 1915 by color photography pioneer Sergei Mikhailovich Prokudin-Gorskii and it shows the mosque's appearance after its collapse in the 1897 earthquake. This work is partially supported by the Ambassador's Fund for Cultural Preservation of the Embassy of USA in Tashkent (Ref. Nr. S-UZ800-17-GR-0043). The expenses associated with renting a terrestrial laser scanner was covered by the Turin Polytechnic University in Tashkent (Uzbekistan), and is greatly appreciated. Special thanks are due to Dr. Sultan Kudratov of the Tashkent University of Information Technologies, Tashkent (Uzbekistan) for his help during the laser scanning in Samarkand. The deployment of the laser scanner and the data reduction of the point clouds was provided by Sensor Fusion and Monitoring Technologies, LLC (USA), and is greatly appreciated. Special thanks are due to Holly Halligan of UC Berkeley for editing the paper. The paper's registration fee required for the participation in the 12th International Conference on Structural Analysis of Historical Constructions, SAHC 2020, was sponsored by University of California, Berkeley, and is greatly appreciated. 


\section{REFERENCES}

[1] Ratiia, Sh. E. (1950) Mechet Bibi-Khanym. Moscow: Gosudarstvennoe izdatelstvo arkhitektury i gradostroitelstva.

[2] Zakhidov, Pulat (1996) Architectural glories of Temur's era. Tashkent: Sharq.

[3] Paskaleva, Elena (2012) The Bibi Khanum Mosque in Samarqand: Its Mongol and Timurid Architecture. The Silk Road 10: 81-98.

[4] Paskaleva, Elena (2013) Epigraphic restorations of Timurid architectural heritage. https://www.academia.edu/3703325/Epigraphic restorations of Timurid architectural heritage. International Institute for Asian Studies. Retrieved 22 January 2021.

[5] Leica Geosystems AG (2011) Leica ScanStation C10: Product Specifications. https://w3.leica-geosystems.com/downloads123/hds/hds/ScanStation\%20C10/brochuresdatasheet/Leica_ScanStation_C10_DS_en.pdf. Accessed January 32020.

[6] Leica Geosystems AG (2015) Cyclone Version 9.1.

[7] The MathWorks Inc (2019) Matlab Version R2019b.

[8] Takhirov, Shakhzod \& Gilani, Amir \& Quigley, Brian \& Myagkova, Liliya. (2018). Assessment of Seismic Vulnerability and Retrofit Strategies of a Historic Building on the Great Silk Road Based on its Current Condition Captured by Laser Scans.

International Journal of Architectural Heritage. 1-13. 10.1080/15583058.2018.1497231.

[9] Shakhzod Takhirov, Khalid M. Mosalam, Mohamed A. Moustafa, Liliya Myagkova, and Brian Quigley (2015) LASER SCANNING, MODELING, AND ANALYSIS FOR

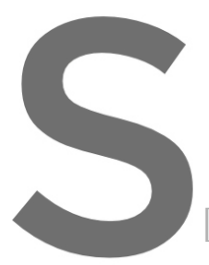
DAMAGE ASSESSMENT AND RESTQRATION OF
COMPDYN 2015.5th ECCOMAS Thentatic Conferenc
Structural Dynainics and Earthquake Engineering. M. Pr
V. Plevris (eds.). Crete Island, Greece, 25-27 May 2015
Shakhzod Takhirov, Amir Gilani, Brian Quigley, Liliya of Seismic Vulnerability of Historic Buildings Based on their Current Condition

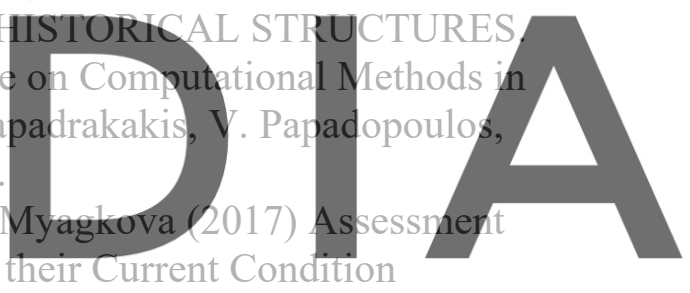
Captured by Laser Scans and Retrofit Strategies. The 16th World Conference on

[11] Francisco M. Fernandes, Paulo B. Lourenço and Fernando CastroChapter. Ancient Clay Bricks: Mianufacture and Properties. Chapter 3 in Mi. Bostenaru Dan et al. (eds.), Materials, Technologies and Practice in Historic Heritage Structures, DOI 10.1007/978-90-481-2684-2_3 , C Springer Science+Business Media B.V. 2009. 